\title{
The influence of built environment to the trends in commuting journeys in the Netherlands
}

\author{
Yusak O. Susilo $\cdot$ Kees Maat
}

Published online: 27 June 2007

(C) Springer Science+Business Media B.V. 2007

\begin{abstract}
In this paper we describe commuting trends in the Netherlands in the past decade and examine the influence of urban form and travel accessibility on commuting journeys over time on the basis of data from the Dutch National Travel Survey. Exploratory analysis is performed to identify changes in commuting participation, departure time, commuting time, commuting distance and the modal split. Regression analysis and choice models are used to examine the influence of the built environment on commuting parameters over time. The results indicate that urban form has consistently influenced the parameters of commuting journey in the Netherlands in the last 10 years. However, the trend of the influence is unique for each commuting model. Some influences have become less significant in the last decade and some have become stronger.
\end{abstract}

Keywords Commuting behaviour · Long-term analysis · Dutch National Travel Survey · Urban form

\section{Introduction}

The socio-economic and spatial structures of many metropolitan areas have changed significantly in recent decades. Alongside growing prosperity and profound economic changes (e.g. de-industrialisation), the increase in car ownership after World War II was one of the main forces behind the de-concentration of land use. The trend towards motorisation and suburbanisation has greatly affected the way people travel (Cohen and

Y. O. Susilo (ه) $\cdot$ K. Maat

OTB Research Institute for Housing, Urban and Mobility Studies, Delft University of Technology,

P.O. Box 5030, 2600 GA, Delft, The Netherlands

e-mail: y.susilo@tudelft.nl

K. Maat

e-mail: c.maat@tudelft.nl 
Kocis 1980; Kollo and Purvis 1984; Levinson and Kumar 1994). Changes in jobs, homes and residential locations have been particularly instrumental in shaping commuting patterns. For example, many studies have shown that the relocation of urban functions from city cores to suburban development nodes or city outskirts, tends to be accompanied by a decline in mass transit, cycling and walking, and promotes the use of private cars for commuting (Cervero and Landis 1992; Schwanen et al. 2001; Cervero and Wu 1998).

Most previous studies draw on analyses of cross-sectional data gathered at a single point in time. Hence, the influence of the built environment on long-term commuting trends is still largely unknown. One could reasonably expect the changes that have occurred in household structure, employment participation and travel accessibility in recent decades to be accompanied by changes in the travel behaviour of commuters (Cervero 1996; Roberts 1986; Van Beek et al. 1997; Kitamura et al. 2003; Dargay and Hanly 2004). For example, Susilo and Kitamura (2006) report that the daily travel and activity engagements of commuters are not stable, but tend to expand continuously over time. If this is true, it is unlikely that the influence of metropolitan structures on commuting journeys will remain steady for longer periods. In addition, differences in metropolitan structure and the accessibility of travel might encourage differences in the change tendencies.

It would be useful if we could gain a clearer understanding of changes in the influence of metropolitan structure on commuting journeys over time as it might help to explain the interaction between land use and transport. It might also help us to project future travel patterns and to work out policy responses to land and transportation development.

Drawing on data from the Dutch National Travel Survey (NTS), this paper traces the trends in commuting journeys in the Netherlands throughout the last decade and examines the influence of urban form and travel accessibility on commuting journeys over time. It also addresses the issue of urban development policy in relation to the changes of commuters' travel behaviour over time.

We begin with a brief review of the literature on the influence of the built environment on commuting patterns and describe the dataset. We discuss shifts in the prevalence of commuting from the home municipality, commuter departure times, commuting time and distance, and the modal split among commuters in the Netherlands between 1993 and 2005. This is followed by the results of regression analyses and choice models which were used to examine the influence of the built environment on commuting parameters at three points in time: 1995, 2000 and 2005. We conclude with a summary and discussion of the results.

\section{The influence of the metropolitan structure on commuting patterns}

There is a growing body of research concerned with the relationship between urban form and travel patterns originates from a diversity of sources and encompass a variety of geographic scales and locations. Some of this research supports the view that various aspects of land use are linked with travel patterns or travel behaviour (for example, Banister 1997; Cervero and Kockelman 1997; Ewing 1995; Frank and Pivo 1994; Meurs and Haaijer 2001; Naess and Sandberg 1996; Newman and Kenworthy 1989; Stead 2001), although in most of this literature only limited effects have been found.

Moreover, the empirical findings accumulated thus far are not entirely consistent. For every piece of empirical evidence demonstrating a link between urban form and travel patterns a counterclaim can almost always be found. For example, some authors (Levinson and Kumar 1984; Gordon and Richardson 1997; Giuliano and Small 1993; Gordon and 
Wong 1985) have suggested that decentralised urban structures tend to reduce both the distance and time of commuting trips. These authors have developed the 'co-location' hypothesis, which claims that firms and households re-adjust spatially from time to time in order to strike a balance in average commuting times and distances. Other researchers (Cervero 1996; Newman and Kenworthy 1989; Ewing 1997) contest this favourable interpretation of the effect of decentralised development on travel behaviour. Ewing (1997) reports that the average commuting time in US metropolitan areas increased during the 1980s and was significantly longer in the suburbs than in the central cities. Naess (2006) also found that, in the Copenhagen region, suburban dwellers travel substantially longer total distances than inner-city residents. In the Netherlands, however, Snellen et al. (2005) found hardly any connection between urban characteristics and kilometres travelled. Schwanen et al. (2003) argue that the co-location hypothesis is less applicable in the European context because Europeans tend to get more attached to the places where they live.

When it comes to mode of transport, a number of researchers have found that the deconcentration of urban land use into suburban locations and new towns almost certainly promotes the use of private cars for all purposes. It also leads to a decline in the use of public transport and in cycling and walking (Cervero and Landis 1992; Schwanen et al. 2001; Cervero and Wu 1998). Kitamura et al. (2003) arrive at a different conclusion, however, and argue that dense public-transport network areas have maintained the share of the modal split among travellers in commercial or central areas for the last three decades. Only in newly urbanised areas, which have less access to public transport, have transit users significantly shifted from public transport to private cars. Similar results are reported in Bolotte's study of the Paris region (Bollote 1991).

Differences in empirical findings might be due to differences in the methodologies and socio-demographic backgrounds employed in previous studies. As mobility is a derived demand, different individuals with different socio-demographic characteristics and different accessibilities and spatial opportunities generate different activity-travel patterns (Hanson 1980; Herz 1983; Pas 1984; Kitamura 1988). Schwanen et al. (2003) report that the characteristics of individuals and their positions in the household have a stronger influence on commuting times by car than the urban structure in which people reside and work. Timmermans et al. (2003) also note that attitudes are apparently more important in shaping activities within a given society than the specific characteristics of urban structures and transport systems.

The discovery that individual characteristics are the main explanatory factor for the relationship between urban form and travel patterns raises a new question. Given the changes that have occurred in household structure, employment participation, travel accessibility and choice of travel mode in recent decades, it would be reasonable to expect that individual behaviour (in this case, commuter behaviour) has changed as well. To the best of our knowledge, however, the influence of the built environment on commuting journeys over a longer period, particularly in the European context, is yet to be examined.

It is important to be aware of a number of fundamental differences between the urban residential characteristics of Europe and the US. In Europe, relatively more people live in cities with between 200,000 and one million inhabitants. In addition, European cities tend to have a higher density across space than US cities, where urban development is more often privately financed and less subject to government policy. In contrast, many European cities have implemented measures to limit urban sprawl and promote the development of compact urban forms as a means of reducing energy consumption by transport. As a result, car ownership is lower in Europe than in US, as is the use of and dependence on cars. 
In addition, far more people use public transport and bicycles in Europe than in the US (Orfeil and Bovy 1993; Kenworthy and Laube 1999; Schwanen et al. 2002). What counts for Europe, count even more for the Netherlands: the urban density across space and the share of bicycle travel are considerably higher than in the neighbouring countries.

This study tests the following hypotheses. Improved accessibility between activity locations in the past decade has caused the influence of the built environment on individual commuting journey parameters to decline. However, urban forms may still have exerted an influence on commuting parameters in the Netherlands over the last 10 years and individual factors may play a greater role than travel accessibility factors in determining the travel behaviour of commuters.

\section{The Dutch national travel survey (NTS)}

The NTS is a cross-sectional travel-diary survey of household travel behaviour in the Netherlands, which has been carried out by Statistics Netherlands since 1978. In 1995, the annual sample size was enlarged from 10,000 to 60,000 households (net response). The survey compiles data on travel behaviour, providing information on $\sim 600,000$ trips made by 150,000 individuals every year (Schwanen et al. 2001; Evert and Moritz 2000).

There are two major concerns with regard to long-term analysis based on the Dutch NTS. First, the NTS was improved twice during the period covered by the models (19952005): the Kontiv design was implemented (from 1998 to 1999) and changes were made to the sampling frame (from 2003 to 2004). These improvements could undermine the comparability of the survey results. Second, administrative reforms between 1995 and 2005 reduced the number of municipalities in the Netherlands from 633 to 467. Some municipalities in suburban areas with a population of $<10,000$ were merged to create larger administrative units. Unfortunately, the travel-diary data was collected every year on the basis of the municipality code. As this has changed in the meantime it is virtually impossible to group the all survey results under one consistent code.

However, after observing the results collected between 1993 and 2005, it can be assumed that the travel parameters, such as travel distance and travel time, were still comparable (see Fig. 1 for the trend of the weighted observed values). Nevertheless, these conditions will, at all events, be taken into account in the analyses. Furthermore, to avoid ambiguous results, the data that collected from the municipalities which been merged during the observed period are excluded in the analyses (about $5 \%$ of the total sample).

The analysis in this study focuses on full-time workers (i.e. people who are employed at least $30 \mathrm{~h}$ a week) who made at least one work-related trip on the surveyed day, whose travel origin and destination were in the Netherlands, and who started and ended their daily trip at their home location (hereafter referred to as commuters). We define a commuting journey as a series of trips that originates and ends at either the home base or the work base. It is important to be reminded here that this paper is not a complete description of worker's travel behaviour in the Netherlands since $36 \%$ of the employees in the Netherlands are part-time worker (OECD 2007).

In this study, the built environment data were collected on a municipality basis for each respective year. Due to the limited availability of land-use data, analysis is possible only from 1993 onwards. This paper classifies the urban form according to the degree of urbanisation of the city (based on the number of addresses per $\mathrm{km}^{2}$ ). The urban areas are split into five groups: very highly urbanised, highly urbanised, moderately urbanised, low 


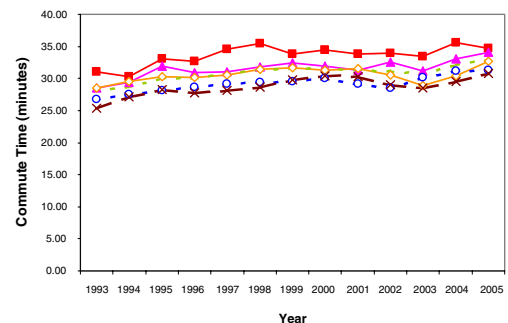

(a) Daily commuting-journey time (in minutes)

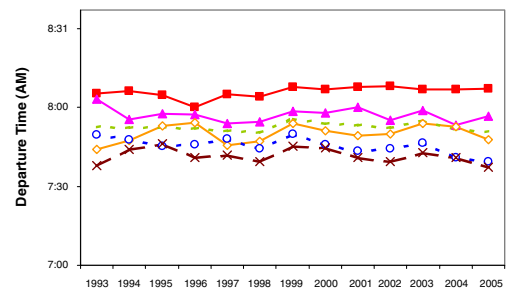

(c) Commuting departure time

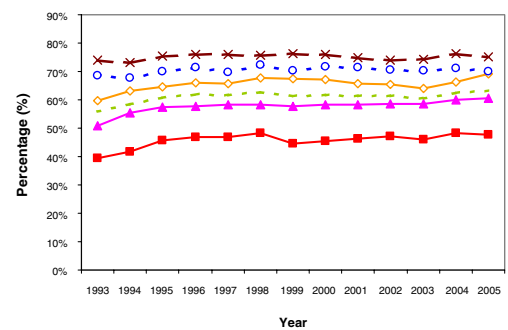

(e) Percentage of commuters who commute outside their home municipalities

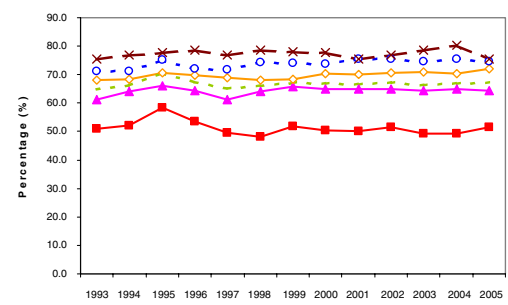

Year

(g) Percentage of automobile commuters

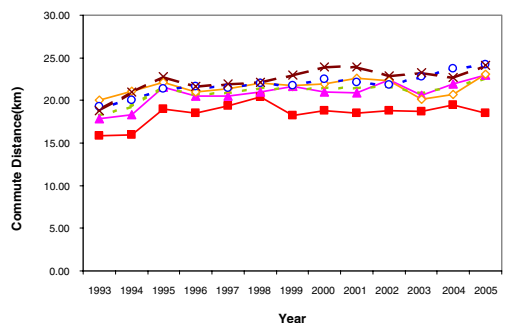

(b) Daily commuting-journey distance

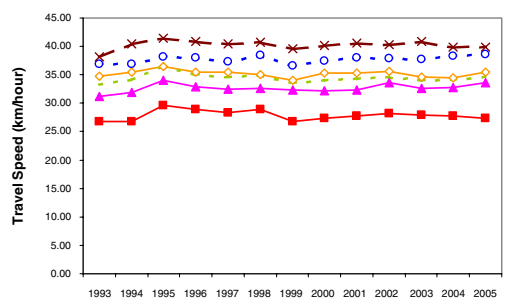

Year

(d) Commuting speed (km/hour)

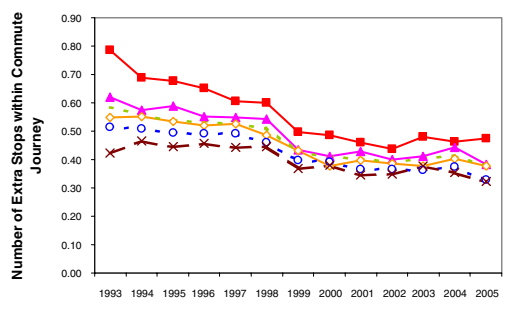

Year

(f) Number of extra stops in commuting journey

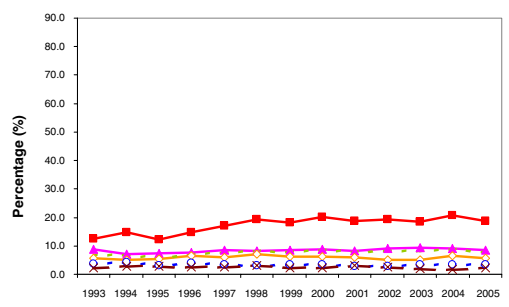

Year

(h) Percentage of train/bus/tram/metro commuters

\begin{tabular}{lll|}
\hline$\rightarrow-$ Very Highly Urbanised & $\longrightarrow$-Highly Urbanised & $\longrightarrow$ Moderately Urbanised \\
$-\infty-$ - Low Urbanised & $-\leftarrow$ Non-Urbanised & $\cdots$ Average
\end{tabular}

Fig. 1 Trends in the parameters of commuting in the Netherlands according to degree of urbanisation of the home municipality 
urbanised and non-urbanised (see Table 1). The analysis also includes other socio-demographic aspects of the area, such as population, local job opportunities, public transport and road network densities and travel accessibility.

Table 1 Variables used in the study

\begin{tabular}{|c|c|}
\hline Variable & Description \\
\hline Male & Dummy variable for male individuals \\
\hline Younger than 25 & Dummy variable for people younger than 25 \\
\hline Aged 25-39 & Dummy variable for people between the ages of 25 and 39 \\
\hline Aged 40-64 & Dummy variable for people between the ages of 40 and 64 \\
\hline Aged 65 or over & Dummy variable for people aged 65 or over \\
\hline Dependent children & The presence of children younger than 12 \\
\hline $\begin{array}{l}\text { Number of household } \\
\text { members }\end{array}$ & Number of household members \\
\hline Income $[x € 1,000]$ & Personal income after taxes \\
\hline High education & The individual has a university or polytechnic degree \\
\hline Car availability & The individual has a driving licence and there is at least one car in the household \\
\hline Population & Number of inhabitants in the individual's home municipality \\
\hline Very highly urbanised & Home municipality has $\geq 2,500$ addresses per $\mathrm{km}^{2}$ \\
\hline Highly urbanised & Home municipality has $1,500-<2,500$ addresses per $\mathrm{km}^{2}$ \\
\hline Moderately urbanised & Home municipality has $1,000-<1,500$ addresses per $\mathrm{km}^{2}$ \\
\hline Low urbanised & Home municipality has $500-<1,000$ addresses per $\mathrm{km}^{2}$ \\
\hline Non-urbanised & Home municipality has $<500$ addresses per $\mathrm{km}^{2}$ \\
\hline Located in $\mathrm{RMA}^{\mathrm{a}}$ & Home municipality is located in Randstad Metropolitan Area (RMA) \\
\hline RMA main cities ${ }^{\mathrm{a}}$ & Home municipality is Amsterdam, The Hague, Rotterdam or Utrecht \\
\hline Job availability & Number of jobs per 1,000 inhabitants in home municipality \\
\hline Job accessibility by car & Number of jobs that can be reached by car within $30 \mathrm{~min}$ \\
\hline Job accessibility by rail & Number of jobs that can be reached by rail within $30 \mathrm{~min}$ \\
\hline Job accessibility & Number of jobs that can be reached by car or rail within $30 \mathrm{~min}$ \\
\hline Population accessibility & Number of individuals that can be reached by car or rail within $30 \mathrm{~min}$ \\
\hline Network density & Total land-use density for transportation network in home municipality \\
\hline $\begin{array}{l}\text { Distance from train } \\
\text { station }\end{array}$ & Average distance from the closest train station in home municipality $(\mathrm{km})$ \\
\hline $\begin{array}{l}\text { Distance from metro } \\
\text { station }\end{array}$ & Average distance from the closest metro station in home municipality $(\mathrm{km})$ \\
\hline $\begin{array}{l}\text { Distance from motorway } \\
\text { access }\end{array}$ & Average distance from the closest motorway access in home municipality $(\mathrm{km})$ \\
\hline Commuting by car & Main mode of transport for commuting is car \\
\hline $\begin{array}{l}\text { Commuting by train/bus/ } \\
\text { metro }\end{array}$ & Main mode of transport for commuting is train, bus or metro \\
\hline $\begin{array}{l}\text { Commute by non- } \\
\text { motorised mode }\end{array}$ & $\begin{array}{l}\text { Main mode of transport for commuting is walking, cycling or snorfiets (<50 cc } \\
\text { engine moped, which has usage characteristics similar to the bicycle) }\end{array}$ \\
\hline
\end{tabular}

${ }^{\text {a }}$ Randstad Metropolitan Area $(R M A)$ is an agglomeration in the Netherlands, consisting of the four largest cities (Amsterdam, The Hague, Rotterdam and Utrecht) and the surrounding areas. With 7.5 million inhabitants (almost half the population of the Netherlands) it is one of the largest agglomerations in Europe. In the middle of the four main cities, is an area called the Green Heart, which is a large open green space with some villages, industrial estate and medium-sized cities 


\section{Trends in commuting journey in the Netherlands}

The trends in commuting journeys' parameters from 1993 to 2005 are shown in Fig. 1. The figures have been weighted by the trip weigh factor that provided by the NTS. The results are classified according to the degree of urbanisation of the home municipality, which is based on the density of the addresses (see Table 1 for further descriptions of the variable).

Overall, in the last 12 years, the commuters' total daily travel distance and daily travel time have increased by $7.5 \%$ and 4.4\%, respectively. Between 1993 and 2005 commuting distance and commuting time have increased by $23 \%$ and $17 \%$, respectively (Fig. 1a, b). It also shown that although commuters from less urbanised areas travel longer commuting distances, they actually spend less time commuting, as they tend to travel at higher speeds than commuters from more urbanised areas (Fig. 1c). Slower traffic in very highly urbanised areas has made the commuters from these areas are able to travel at an average of only $69 \%$ of the travel speed of commuters from non-urbanised areas. On average, the commuting speed in the Netherlands is $34.5 \mathrm{~km} / \mathrm{h}$.

Interestingly, although the commuters living in less urbanised areas could reach their work faster than those living in more urbanised areas, they tend to leave home earlier than commuters from more urbanised areas (Fig. 1d). The idea of living in the suburbs (which are located farther from activity centres or workplaces and thus add to uncertainty in commuting time) apparently prompts suburban commuters to set off earlier.

It also appears that the percentage of individuals who commute to areas outside their home municipality is higher for those who live in less urbanised areas than for those who live in more urbanised areas (Fig. 1e). The results do, however, show intensive and extensive commuting movements (cross-commuting) between municipal areas. Approximately $76 \%$ of commuters who live in non-urbanised areas and almost half the commuters who live in very highly urbanised areas commute outside their home municipalities. It is also shown that from 1993 to 2005, the fraction of more urbanised areas' commuters who commute to outside their home municipality has slightly increased, whilst the fraction from less urbanised areas' commuters tend to be stable.

More activity opportunities in more urbanised areas have encouraged commuters who live in these areas to incorporate more stops in their commuting journeys (Fig. 1f). Interestingly, unlike commuting journeys in other countries where the number of extra stops is on the increase (McGuckin et al. 2005; Kitamura and Susilo 2006), the average number of extra stops in Dutch commuting journeys has dropped by 35\% since 1993. This trend might be due to the fact that stores and supermarkets have extended their opening hours, thus encouraging Dutch commuters to make separate trips rather than combining them with their commuting journeys. It is clearly shown in Fig. 1f that two major NTS survey improvements (in 1998/1999 and 2003/2004) contributes to the differences of the reported number of trips between periods. Interestingly, although commuters from very highly urbanised areas make about 50\% more trips than commuters from non-urbanised areas, the additional time and distance for the extra stops are comparable with those of commuters in less-urbanised areas (not shown in the figure).

As expected, more urbanised areas tend to have more public-transport and non-motorised commuters (not shown in the figure) and fewer private-car commuters (Fig. 1g, h). The use of private cars as a commuting mode in the Netherlands has remained relatively stable in the last 12 years, whilst there were slight increased in the use of public transport and slight decreased in non-motorised mode, especially in very highly urbanised areas. 


\section{Who tends to commute outside the home municipality?}

A binomial logit model was used to examine the influence of the built environment and individual socio-demographic conditions on the rate of commuting from the home municipality. Estimates were performed for three points in time (1995, 2000 and 2005) to determine whether the influence of the variables was consistent over recent decades. The results of this analysis are presented in Table 2 according to the following values: a value of 0 indicates that the commuter's workplace is inside the home municipality and a value of 1 indicates that it is outside the home municipality. The table only shows the significant variables.

The comparison of the built environment influence overtime in this paper is done as follow. First, examine the trend of each built environment variables' coefficients overtime. Second, test the contribution of built environment variables as one block to the overall fitness of the model overtime. To achieve the second objective, two models configuration are estimated for each observed year: model 1 estimated based on individual sociodemographic variables only and model 2 estimated based on both individual sociodemographic and built environment variables. Based on these two models' outputs, the contribution of built environment as one whole unit to the fitness of the model fit over time is examined.

As shown in Table 2, commuters who live in more populous and more urbanised areas tend to work inside their home municipalities in contrast with commuters who live in less populous and less urbanised areas. Males tend to commute more than females outside their home municipality. The presence of dependent children reduces the possibility of commuting outside the home municipality, although the influence is marginal. Younger workers tend to commute to locations outside their home municipality, while older workers tend to work in the municipalities in which they live.

The results also show that the job-housing balance (the number of jobs per number of inhabitants) significantly reduces the likelihood that commuters will commute outside their home municipality. That said, highly paid and highly skilled commuters tend to look beyond their home municipality for jobs that are commensurate with their skills and salaries. This result is consistent with some previous studies (e.g. Schwanen et al. 2001; Cervero 1996). Higher job accessibility, denser transport networks and access to a car also increase the chance of people working outside their home municipality. Commuters who live in the Randstad tend to cross-commute while those who live in the main cities of Randstad tend to work within their home municipality.

Interestingly, the significance and the influence of the as degree of urbanisation variables, except for low urbanised area, declined between 1995 and 2005 whilst the influence of other built environment variables, such as transport accessibility, slightly decreased in 2000 and increased again in 2005. The coefficient of very highly urbanised area is -1.26 in 1995 with t-stats -15.90 , compared with -1.12 with t-stats -13.58 in 2000 and with -1.08 with $t$-stats -8.68 in 2005 . The coefficient of job accessibility is 0.46 in 1995 , became 0.44 in 2000 and 0.48 in 2005 . This implies that, whilst the influence of accessibility has increased in the last decade, the home location has become less important in influencing the commute behaviours.

The inclusion of built environment variables to the models increases the fitness of the model (log likelihood values) 3.78\% in $1995,3.12 \%$ in 2000 and $3.23 \%$ in 2005 . 


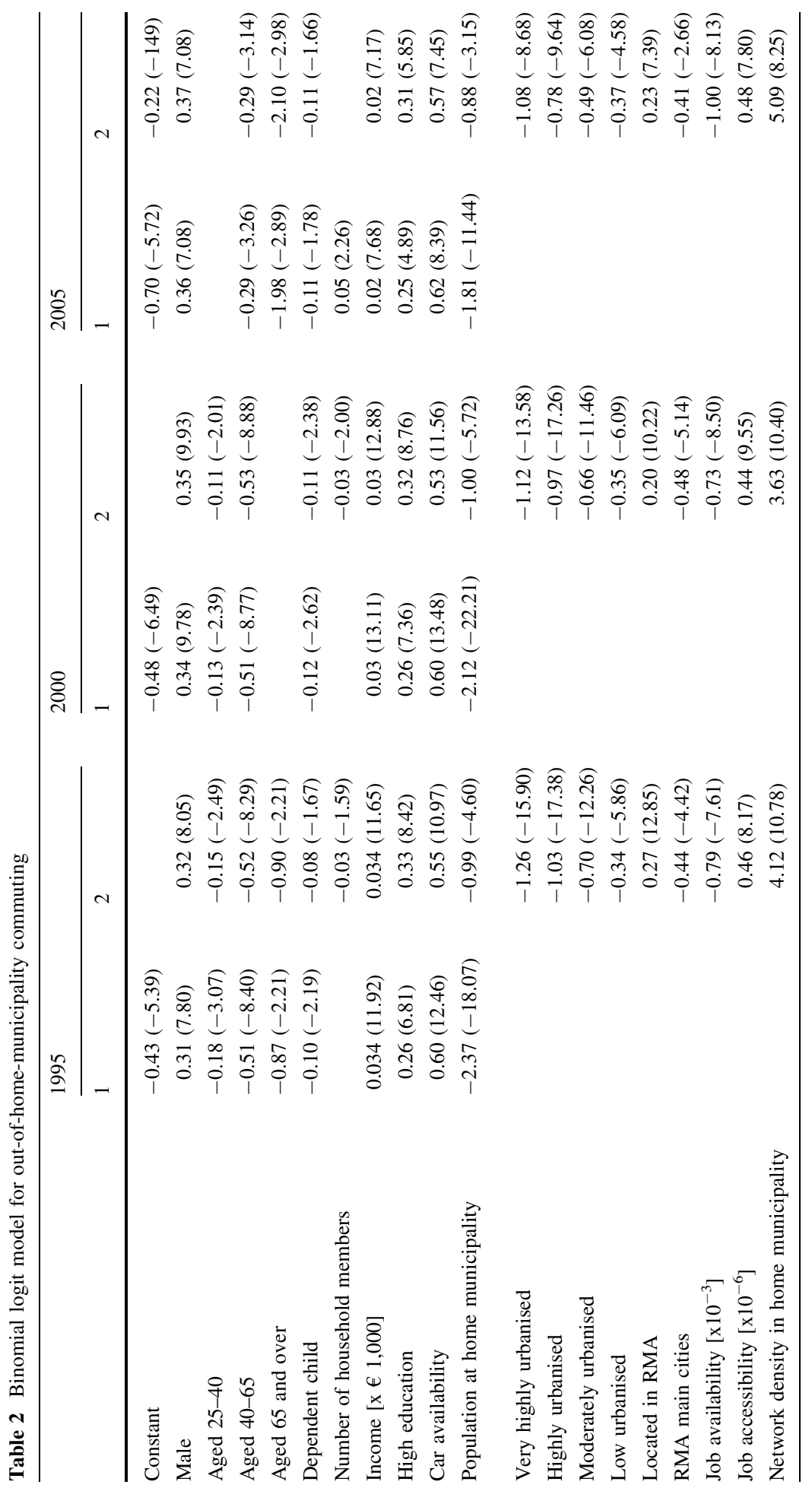




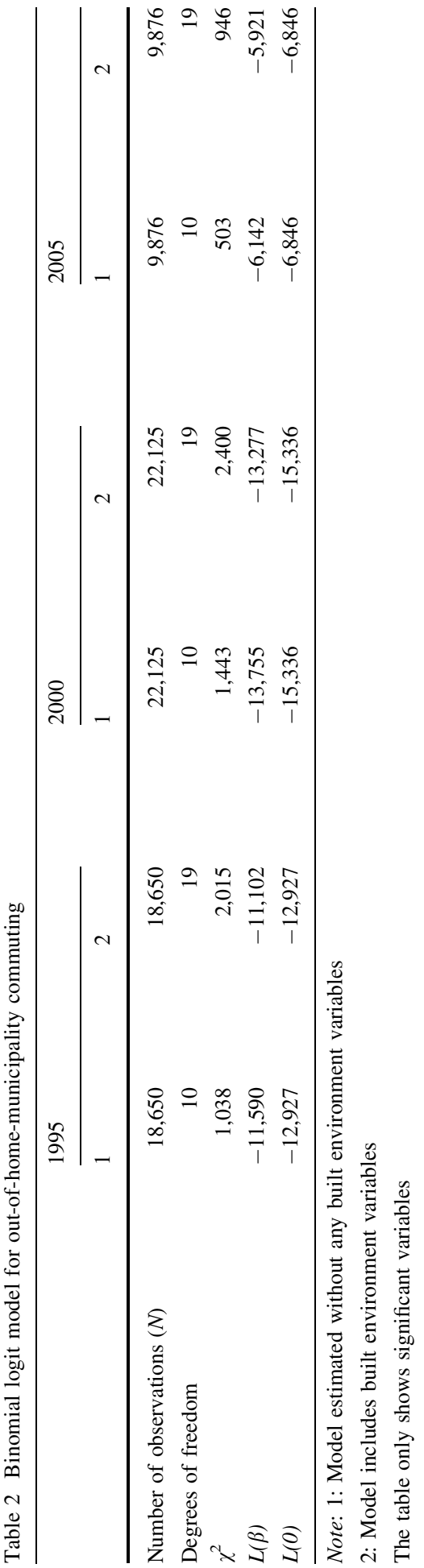




\section{How far do they commute?}

A regression model was used to examine the influence of urban form and socio-demographic conditions on commuting distances in the Netherlands between 1995 and 2005. This paper does not afford enough scope to show the results here.

The estimated models do show, however, very low coefficients of determination $\left(R^{2}\right)$ - below 0.05-and some coefficients switched signs across the study year. Moreover, neither the population of the city nor the transport variables exerted a consistent significant influence on commuting distance. Job accessibility and degree of urbanisation variables only give marginal influences in the models. These findings show that the commuter's workplace (and commuting distance) is barely influenced by urban size or factors relating to travel accessibility, but rather by factors which have not been accounted for in this analysis, such as jobs suited to individual tastes and abilities, a better environment for work and family life, etc. This finding bears out Van der Laan's argument that commuting destinations and distances are heavily dependent on the job market (Van der Laan 1998).

Be that as it may, the models still offer few significant results. As males tend to commute more than females outside their home municipality, they tend to commute farther. Male commuters travelled 4.8, 5.9 and $6.5 \mathrm{~km}$ farther than female commuters in 1995 , 2000 and 2005, respectively. This finding is consistent with previous studies, which have shown that female commuters in the Netherlands tend to travel shorter distances than their male counterparts (Schwanen et al. 2002). Commuters with higher incomes and higher levels of education tend to travel farther than other commuters and commuters who live in denser areas commute shorter distances than those who live in less dense areas. For example, people from very highly urbanised areas commuted 6.2, 5.5 and $6.7 \mathrm{~km}$ less than people from non-urbanised areas in 1995, 2000 and 2005, respectively. It is understandable since the distance to activity locations is much shorter in dense and compact areas than in sprawl areas. The inclusion of built environment variables increased the models fitness ( $r^{2}$-values) $5.97 \%$ in $1995,5.79 \%$ in 2000 , and $8.32 \%$ in 2005 .

\section{What is the preferred commuting mode?}

We used a multinomial logit model to estimate the influence of the built environment and socio-demographic factors on the preferred commuting mode between 1995 and 2005. The transport modes considered in the model are private car, public transport (train, bus, metro and tram) and non-motorised modes (walking, cycling and snorfiets), with the non-motorised mode as the basic alternative. The results are presented in Table 3.

The results show that access to a car and commuting distance are the main factors that prompt commuters to travel by private car or public transport. Access to a car significantly increases the likelihood of car usage and reduces the likelihood of using public transport. For commute longer distances, Dutch commuters tend to use public transport more than private cars. Interestingly, the results also support the argument that the Dutch are fond of non-motorised modes of transportation (walking and cycling). Taking only the coefficient values of age and commuting distance, it appears that Dutch commuters prefer walking or cycling to private cars or public transport when commuting $<3 \mathrm{~km}$. 


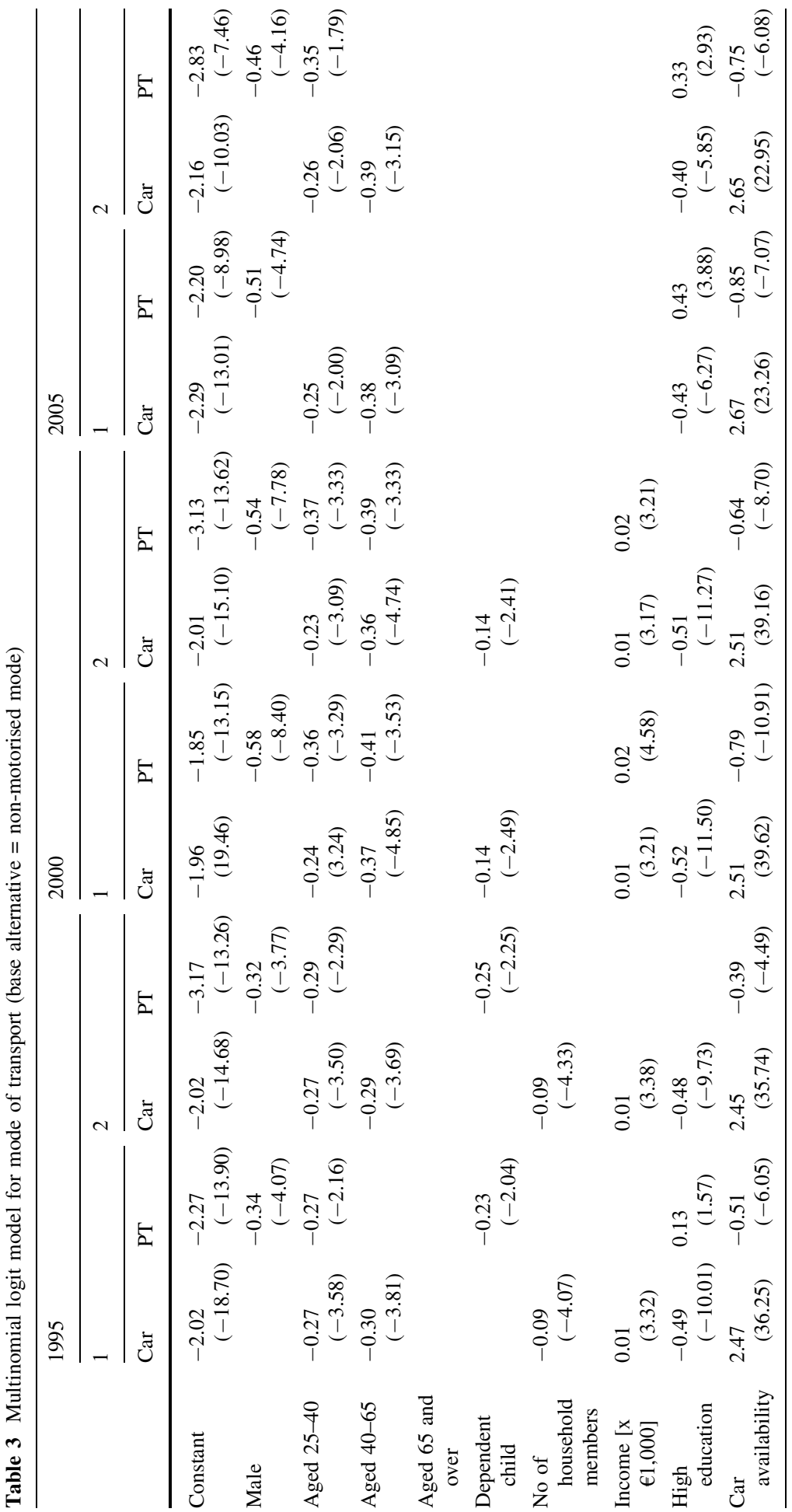




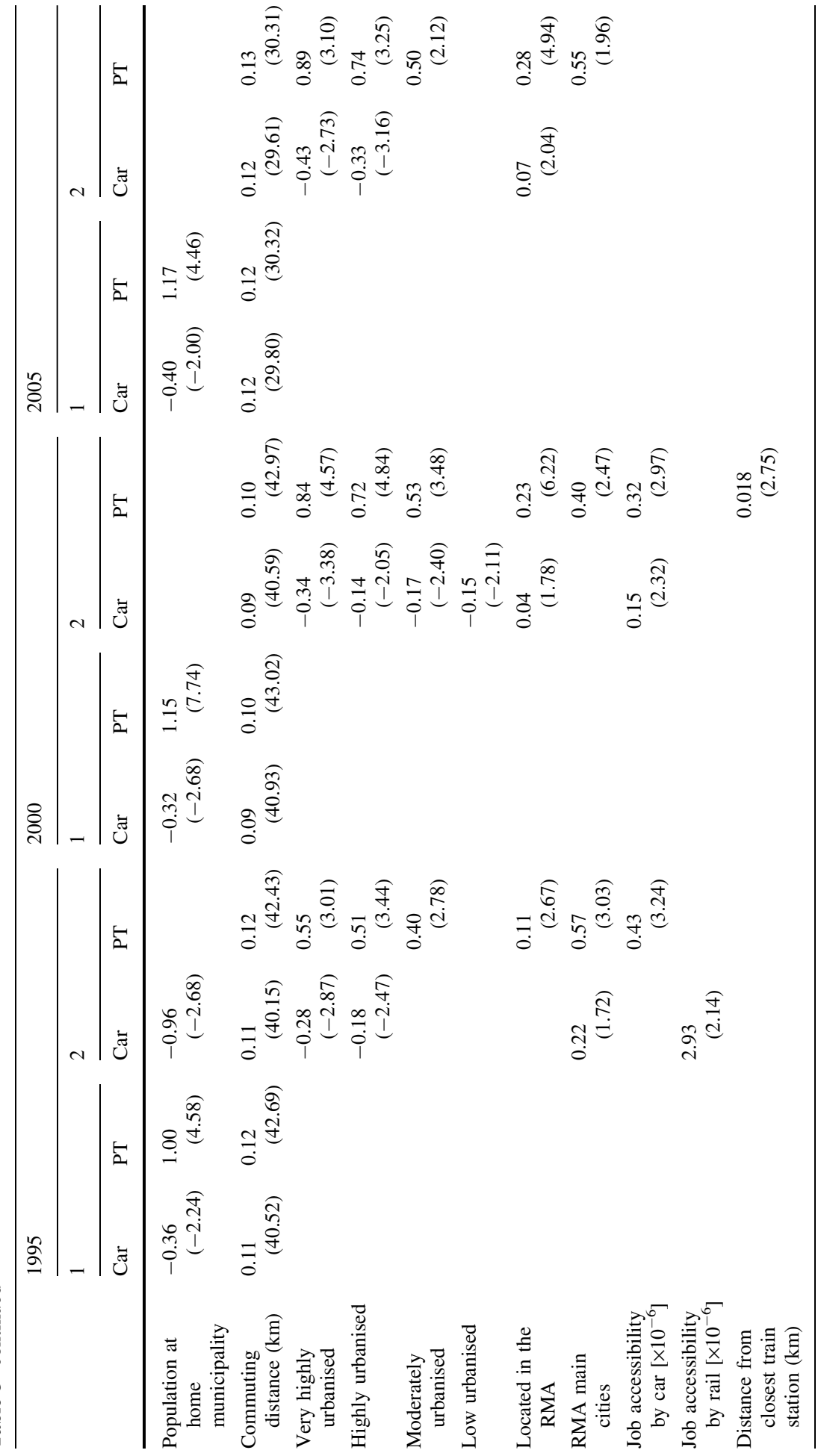




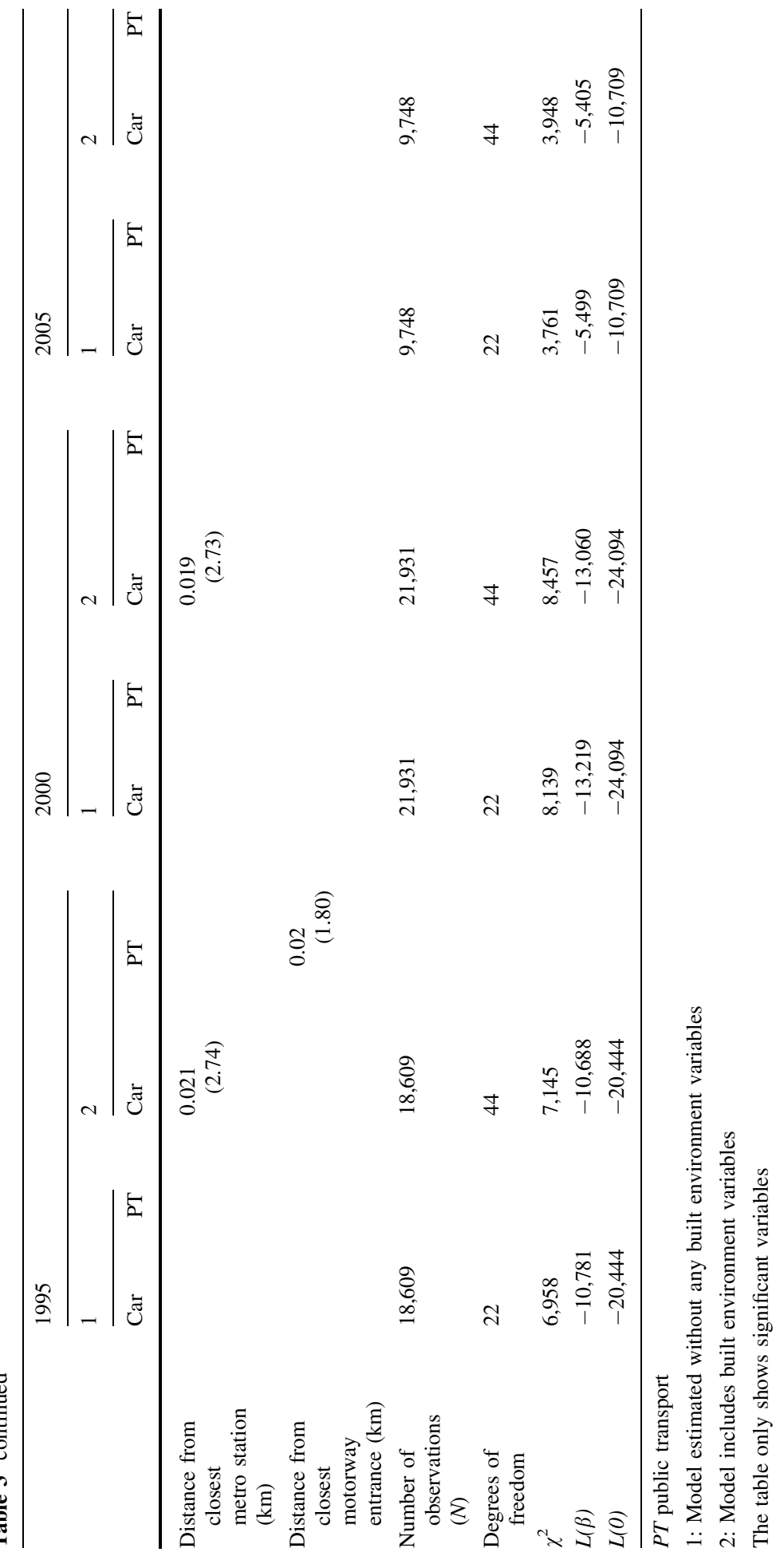


Female commuters tend to use public transport more than male commuters, but there are no gender differences in the propensity to use private cars and non-motorised modes in commuting. The use of private cars is lowest among highly educated commuters.

As expected, commuters from more urbanised areas are more likely to use public transport than commuters from less urbanised areas. Commuters who live in the Randstad and its main cities also tend to use public transport more than commuters who live outside the area.

However, the transport-accessibility variables had no consistent significant effects for the 3 years that were addressed. The influence of dense residential areas to the commuting mode has increased in the past decade. The coefficient of very highly urbanised area in encouraging the use of private car is -0.28 in $1995,-0.34$ in 2000 and -0.43 in 2005. Corresponding figures for public transport modes are 0.55 in 1995, 0.84 in 2000 and 0.89 in 2000.

Interestingly, the coefficients for the commuting distance were relatively stable from 1995 to 2005. The influence of car availability is growing continuously in the last decade, both in encouraging the use of cars and reducing the use of public transport.

The inclusion of built environment variables increased the models fitness (log likelihood values) $0.46 \%$ in $1995,0.66 \%$ in 2000 and $0.87 \%$ in 2005 . This shows that, although only at very marginal level, from 1995 to 2005, the influence of built environment factors to the commuting mode choice in the Netherlands has increased.

\section{How long does the commuting journey take?}

This final section uses a regression model to examine the influence of urban form on commuting times in the Netherlands in the last decade. In order to examine the influence of urban form without endogeneity biases from job market distribution on the location of the workplace (commuting distance) and the exclusive characteristics of each travel mode, the model includes commuting distance and travel mode as explanatory variables. The results are presented in Table 4.

Commuting distance shows a strong positive association with total commuting time (for the obvious reason that commuting distance is roughly proportional to commuting time); an increase of $1 \mathrm{~km}$ in commuting distance was associated with increases in commuting time of $0.71,0.83$ and $0.78 \mathrm{~min}$ in 1995, 2000 and 2005, respectively.

Consistent with the results of previous explanatory analyses, it appeared that, although the average distance travelled by commuters from more urbanised areas was shorter, these commuters actually spend more time travelling. Commuters from very highly urbanised areas travelled 2.34, 3.00 and 2.63 min longer than those from non-urbanised areas in 1995, 2000 and 2005, respectively. Commuters from the Randstad travelled longer than commuters from outside this area.

Taking only the transportation-mode variables, with the same distances and conditions, car commuters travelled $\sim 1.5-2$ min less and public-transport commuters travelled $\sim 16-$ 18 min more than non-motorised commuters.

Overall, the time that commuters spent on commuting increased continuously from 1995 to 2005 . However, while the influence of urban form on commuting time changed overtime, there is not any clear trend of the changes. The inclusion of built environment variables increased the models fitness ( $r^{2}$-values) $0.57 \%$ in $1995,0.33 \%$ in 2000 and $0.35 \%$ in 2005 . 


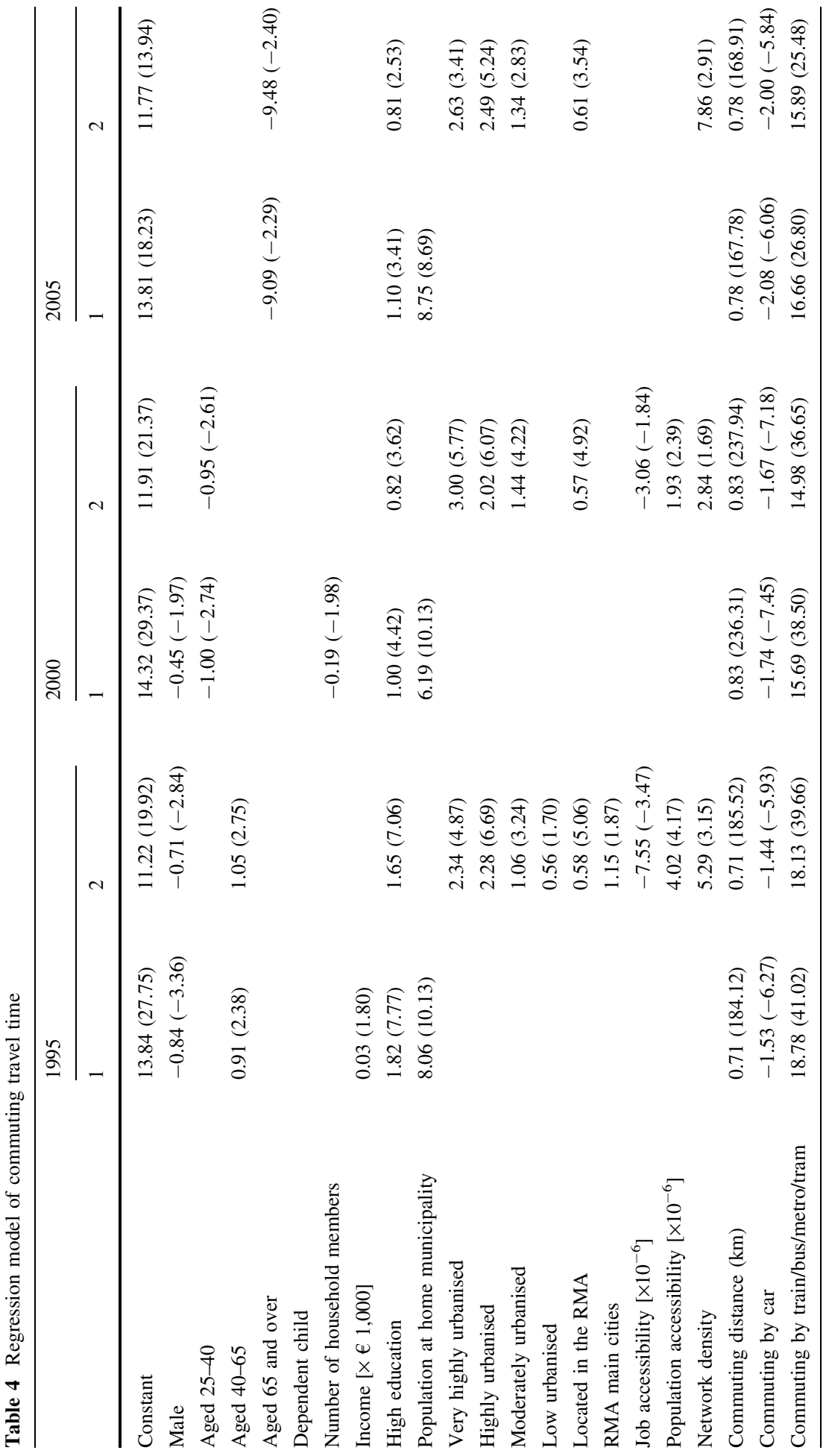




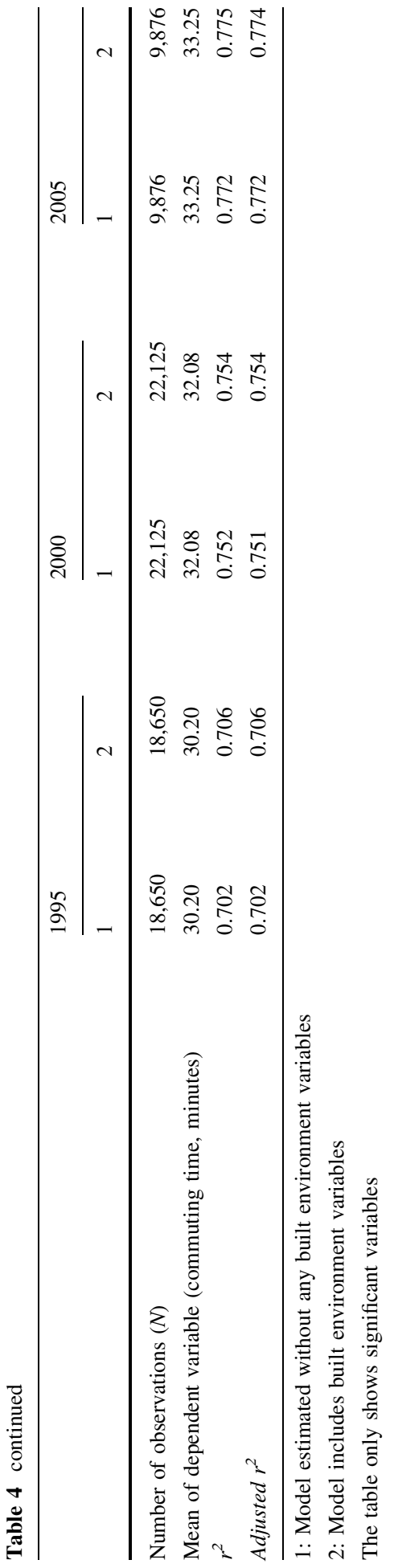




\section{Built environments and journey parameters}

As shown in Tables 2, 3, 4, the built environment factors, such as urban form and accessibility indices, consistently influence commuting trends in Netherlands in the last decade. The influence of the various factors is summarised in Table 5. The salient trends are as follows:

- As cities become more urbanised and compact, cross-commuting between municipalities, commuting distances, and car use for commuting are likely to decrease. Commuting time is likely to increase, however, because of the lower commuting speed. On the other hand, the use of public transport is likely to increase.

- The growth in transport-network density and accessibility will increase crosscommuting participation and reduce commuting distances. At the same time, these developments will increase commuting time, as higher transport-network density tends to 'invite' higher numbers of private cars into the area and to make networks more congested.

- Interestingly, increasing travel accessibility does not have a significant influence on the commuters' choice of transport mode. As is clearly shown by the estimation results in Table 3, commuting distance (i.e. location of the workplace) and car availability are the factors upon which commuters are most likely to base their choice of transport mode. This relationship is strengthened by very good highway accessibility with a high average commuting speed $(34.5 \mathrm{~km} / \mathrm{h})$ in the Netherlands, which make any improvement in accessibility side would hardly encourage the commuters' to shift from private car. Improvements in the scope of public transport may nonetheless

Table 5 Influence of the built environment on Dutch commuting journeys

\begin{tabular}{|c|c|c|c|c|c|}
\hline $\begin{array}{l}\text { Urban form and } \\
\text { accessibility }\end{array}$ & $\begin{array}{l}\text { Cross- } \\
\text { commuting }\end{array}$ & $\begin{array}{l}\text { Commuting } \\
\text { distance }\end{array}$ & $\begin{array}{l}\text { Commuting } \\
\text { time }\end{array}$ & $\begin{array}{l}\text { Use of private car } \\
\text { as a transport mode }\end{array}$ & $\begin{array}{l}\text { Use of public transit } \\
\text { as a transport mode }\end{array}$ \\
\hline More urbanised area & - & - & + & - & + \\
\hline Less urbanised area & + & + & - & + & - \\
\hline Job-housing balance & - & & & & \\
\hline $\begin{array}{l}\text { Job accessibility } \\
\text {-Rail accessibility }\end{array}$ & + & & $-^{\mathrm{a}}$ & & \\
\hline $\begin{array}{l}\text { Transport-network } \\
\text { density and } \\
\text { accessibility }\end{array}$ & + & & $+^{\mathrm{a}}$ & & \\
\hline $\begin{array}{l}\text {-Distance from train } \\
\text { station }\end{array}$ & & & & & $+^{\mathrm{a}}$ \\
\hline $\begin{array}{l}\text { Became part of the } \\
\text { Randstad }^{\text {c }}\end{array}$ & + & & + & $t^{\mathrm{a}}$ & + \\
\hline $\begin{array}{l}\text { As one of main } \\
\text { Randstad cities }^{c}\end{array}$ & - & & $+{ }^{a}$ & $+^{\mathrm{a}}$ & + \\
\hline \multicolumn{6}{|l|}{+ Positive influence } \\
\hline \multicolumn{6}{|l|}{-: Negative influence } \\
\hline \multicolumn{6}{|c|}{ a Not consistently significant from 1995 to 2005} \\
\hline \multicolumn{6}{|c|}{${ }^{\mathrm{b}}$ Non-motorised mode (walking, cycling and snorfiets) is the base alternative } \\
\hline
\end{tabular}


increase the use of public transport, although this factor did not exert a constant significant influence in the period studied.

- The development of large polycentric networks, as in the Randstad, offers a convenient environment for cross-commuting, which tends to increase traffic flow and congestion, while also increasing the use of public transport.

The analyses also show that influences have changed in the last decade. However, the trend of changes is unique for each analysis. In cross-commuting analysis, while the influence of accessibility has increased, the influence of degree of urbanisation of home location becomes weaker. On the other hand, the influence of urbanised residential areas to the commuting mode choice has increased in the past decade.

In commute distance and commute time models, however, the built environment variables do not show any clear pattern of changes. Moreover, the commuting distance model shows that the commuter's workplace (and commuting distance) is barely influenced by factors relating to urban forms and travel accessibility and more by other factors, such as job market that reflect individual abilities and preferences and the job location distribution. These findings support the argument that individual and other factors are more crucial in determining the travel behaviour of commuters than the built environment and accessibility (Schwanen et al. 2003; Timmermans et al. 2003; Stead 2001).

Compare the contribution of the built environment variables to the model fitness in 1995 and in 2005, it appears that, while the contribution has increased in commute distance and commute mode choice models, it has decreased in cross-commuting participation and commuting time models. These findings raise a concern that, despite stringent urban development policies in the Netherlands in recent decades (Maat et al. 2005), the influence of urban form to commuting behaviour are changing overtime. Some influences have become stronger in the past decade and some influences have weakened. This suggests that urban form policies alone will not be successful; policymakers need to consider other aspects in order to influence individual spatial activities in the area.

\section{Summary}

Using data from the NTS for 1985-2005, we identified trends in commuting journeys in the Netherlands in the last decade and examined the influence of urban form and travel accessibility on commuting journeys over time. The descriptive analyses show that commuting distance and commuting time in the Netherlands have increased continuously over the last 20 years. However, the distribution of commuters across various transport modes has remained relatively constant.

The study also showed that urban form, which represented by degree of urbanisation variables, consistently influences the parameters of commuting journeys in the Netherlands over the past decade. However, the influences are changing overtime and the trends are unique for each model. Some influences have become less significant in the last decade and some have become stronger.

The result also shows that some models are scarcely influenced by factors relating to urban form and travel accessibility that support the argument that individual and other factors, such as job market distribution, are more crucial in determining the travel behaviour of commuters than the built environment and travel accessibility factors. 
Acknowledgement The authors wish to thank Dominic Stead and anonymous reviewers for their constructive comments on an earlier version of this paper.

\section{References}

Banister, D.: Reducing the need to travel. Environ. Plann. B: Plann. Design 24, 437-449 (1997)

Bollote, L.: Transport in Paris and the Ile de France. Built Environ. 17, 160-171 (1991)

Cervero R., Kockelman, K.: Travel demand and the 3Ds: density, diversity and design. Transport. Res. D 2 , 199-219 (1997)

Cervero, R.: Jobs-housing balance revisited: trends and impacts in the San Francisco Bay Area. J. Am. Plann. Assoc. 62, 492-511 (1996)

Cervero, R., Landis, J.: Suburbanization of jobs and the journey to work: a submarket analysis of commuting in the San Francisco Bay Area. J. Adv. Transport. 25, 275-297 (1992)

Cervero, R., Wu, K.L.: Sub-centering and commuting: evidence from the San Francisco Bay Area. Urban Stud. 35, 1059-1076 (1998)

Cohen, G.S., Kocis, M.A.: Components of change in urban travel. Transport. Res. Rec. 775, $42-47$ (1980)

Dargay, J., Hanly, M.: Volatility of car ownership, commuting mode and time in the UK. Paper presented at the 10th World Conference on Transport Research, Istanbul, Turkey, July (2004)

Evert, H. van, Moritz, G.: The new Dutch travel survey. Paper presented at the 9th International Association for Travel Behavior Conference, Queensland, Australia, July (2000)

Ewing R.: Beyond density, mode choice, and single-purpose trips. Transport. Q. 49, 15-24 (1995)

Ewing, R.: Is Los Angeles-style sprawl desirable? J. Am. Plann. Assoc. 63, 107-126 (1997)

Frank, L.D., Pivo, G.: Impacts of mixed use and density on utilitzation of three modes of travel: singleoccupant vehicle, transit and walking. Transport. Res. Rec. 1466, 44-52 (1994)

Giuliano, G., Small, K.A.: Is the journey to work explained by urban structure? Urban Stud. 30, 1485-1500 (1993)

Gordon, P., Richardson, H.W.: Are compact cities a desirable planning goal? J. Am. Plann. Assoc. 63, 95106 (1997)

Gordon, P., Wong, H.L.: The cost of urban sprawl: some new evidence. Environ. Plann. A 17, 661-666 (1985)

Hanson, S.: Spatial diversification and multipurpose travel: implications for choice theory. Geogr. Anal. 12, 245-257 (1980)

Herz, R.: Stability, variability and flexibility in everyday behaviour. In: Carpenter, S., Jones, P. (eds.) Recent Advances in Travel Demand Analysis. Gower Publishing, Aldershot, England, pp. 385-400 (1983)

Kenworthy, J.R., Laube, F.B.: Patterns of automobile dependence in cities: an international overview of key physical and economic dimensions with some implications for urban policy. Transport. Res. A 33, 691-723 (1999)

Kitamura, R.: An evaluation of activity-based travel analysis. Transportation 15, 9-34 (1988)

Kitamura, R., Susilo, Y.O.: Does a grande latte really stir up gridlock? stops in commute journeys and incremental travel. Transport. Res. Rec. 1985, 198-206 (2006)

Kitamura, R., Susilo, Y.O., Fukui, K., Murakami, J., Kishino, K.: The invariants of travel behavior: the case of Kyoto-Osaka-Kobe metropolitan area of Japan, 1970-2000. Paper presented at the 10th Conference of the International Association for Travel Behaviour Research, Lucerne, August (2003)

Kollo, H.P.H., Purvis, C.L.: Changes in regional travel characteristics in the San Francisco Bay Area: 19601981. Transport. Res. Rec. 987, 57-66 (1984)

Levinson, D.M., Kumar, A.: The rational locator: why travel times have remained stable. J. Am. Plann. Assoc. 60, 319-331 (1994)

Maat, K., van Wee B., Stead, D.: Land use and travel behaviour: expected effects from the perspective of utility theory and activity-based theories. Environ. Plann. B 32, 33-46 (2005)

McGuckin, N., Zmud, J., Nakamoto, Y.: Trip-chaining trends in the United States: understanding travel behavior for policy making. Transport. Res. Rec. 1917, 199-204 (2005)

Meurs H., Haaijer R.: Spatial structure and mobility. Transport. Res. D 6, 429-446 (2001)

Næss P.: Accessibility, activity participation and location of activities: exploring the links between residential location and travel behaviour. Urban Stud. 43, 627-652 (2006)

Næss P., Sangberg S.L.: Workplace location, modal split and energy use for commuting trips. Urban Stud. 33, 557-580 (1996)

Newman, P.W.G., Kenworthy, J.R.: Gasoline consumption and cities. A comparison of US cities in a global survey. J. Am. Plann. Assoc. 55, 24-36 (1989) 
OECD.: OECD in Figure 2006-2007, OECD Observer 2006/Supplement 1 (2007)

Orfeil, J.P., Bovy P.: European mobility is different: a global perspective. In: Salomon, I., Bovy, P., Orfeuil, J.P. (eds.) A billion trips a day: tradition and transition in European travel patterns. Kluwer, Dordrecht pp. 13-20 (1993)

Pas, E.I.: The effect of selected sociodemographic characteristics on daily travel-activity behavior. Environ. Plann. A 16, 571-581 (1984)

Roberts, R.A.: Analysis of demographic trends and travel patterns: implications for the future of the Portland transit market. Transport. Res. Rec. 1067, 1-8 (1986)

Schwanen, T., Dieleman, F.M., Dijst, M.: Travel behaviour in Dutch monocentric and polycentric urban systems. J. Transp. Geogr. 9, 173-186 (2001)

Schwanen, T., Dieleman, F.M., Dijst, M.: A microlevel analysis of residential context and travel time. Environ. Plann. A 34, 1487-1507 (2002)

Schwanen, T., Dieleman, F.M., Dijst, M.: Car use in Netherlands daily urban systems: does polycentrism result in lower commute time? Urban Stud. 24, 410-430 (2003)

Snellen, D., Hilbers, H., Hendriks, A.: Nieuwbouw in beweging; Een analyse van het ruimtelijk mobiliteitsbeleid van Vinex (New housing developments on the go; An analysis of the Vinex spatial mobility policy). Ruimtelijk Planbureau, Rotterdam: NAi Uitgevers (2005)

Stead, D.: Relationships between land use, socio economic factors, and travel patterns in Britain. Environ. Plann. B 28, 499-528 (2001)

Susilo, Y.O., Kitamura, R.: Structural changes in commuters' daily travel: the case of auto and transit commuters in the Osaka metropolitan area of Japan, 1980 through 2000, submitted to Transport. Res. A (2006)

Timmermans, H., van der Waerden P., Alves, M., Polak, J., Ellis, S., Harvey, A.S., Kurose, S., Zandee, R.: Spatial context and the complexity of daily travel patterns: an international comparison. J. Transp. Geogr. 11, 37-46 (2003)

Van Beek, P., Kalfs, N., Blom, U.: Gender differences in activities and mobility in the Netherlands, 1975 to 1990. Transport. Res. Rec. 1607, 134-138 (1997)

Van der Laan, L.: Changing urban systems: an empirical analysis at two spatial levels. Reg. Stud. 32, 235247 (1998)

\section{Author Biographies}

Yusak Octavius Susilo is a post-doctoral researcher in the OTB Research Institute for Housing, Urban and Mobility Studies, Delft University of Technology, the Netherlands. His research interest is in travel behaviour, activity-based analysis, land use and transport and transportation in developing countries.

Kees Maat is a senior researcher at Delft University of Technology. His research is concerned with the interrelationships between spatial patterns, spatial behaviour and travel, in particular the influence of land use on activity and travel behaviour. He teaches several spatial and transport subjects at the faculty of Technology, Policy and Management. 